\title{
Partial-arm translocations in evolution of malaria mosquitoes revealed by high- coverage physical mapping of the Anopheles atroparvus genome
}

Gleb N. Artemov', Semen M. Bondarenko', Anastasia N. Naumenko², Vladimir N. Stegniy', Maria V. Sharakhova ${ }^{1,2^{*}}$ and Igor V. Sharakhov ${ }^{1,2^{*}}$ (i)

\begin{abstract}
Background: Malaria mosquitoes have had a remarkable stability in the number of chromosomes in their karyotype $(2 n=6)$ during 100 million years of evolution. Moreover, autosomal arms were assumed to maintain their integrity even if their associations with each other changed via whole-arm translocations. Here we use high-coverage comparative physical genome mapping of three Anopheles species to test the extent of evolutionary conservation of chromosomal arms in malaria mosquitoes.

Results: In this study, we developed a physical genome map for Anopheles atroparvus, one of the dominant malaria vectors in Europe. Using fluorescence in situ hybridization (FISH) of DNA probes with the ovarian nurse cell polytene chromosomes and synteny comparison, we anchored 56 genomic scaffolds to the An. atroparvus chromosomes. The obtained physical map represents $89.6 \%$ of the An. atropanus genome. This genome has the second highest mapping coverage among Anophelinae assemblies after An. albimanus, which has $98.2 \%$ of the genome assigned to its chromosomes. A comparison of the An. atroparvus, An. albimanus, and An. gambiae genomes identified partial-arm translocations between the autosomal arms that break down the integrity of chromosome elements in evolution affecting the structure of the genetic material in the pericentromeric regions. Unlike An. atroparvus and An. albimanus, all chromosome elements of An. gambiae are fully syntenic with chromosome elements of the putative ancestral Anopheles karyotype. We also detected nonrandom distribution of large conserved synteny blocks and confirmed a higher rate of inversion fixation in the X chromosome compared with autosomes.

Conclusions: Our study demonstrates the power of physical mapping for understanding the genome evolution in malaria mosquitoes. The results indicate that syntenic relationships among chromosome elements of Anopheles species have not been fully preserved because of multiple partial-arm translocations.
\end{abstract}

Keywords: Mosquito genome, Chromosome evolution, Partial-arm translocation, Fluorescence in situ hybridization, Physical mapping, Polytene chromosomes, Anopheles atroparvus

\footnotetext{
* Correspondence: msharakh@vt.edu; igor@vt.edu

'Laboratory of Ecology, Genetics and Environmental Protection, Tomsk State

University, 36 Lenin Avenue, Tomsk 634050, Russia

Full list of author information is available at the end of the article
}

(c) The Author(s). 2018 Open Access This article is distributed under the terms of the Creative Commons Attribution 4.0 International License (http://creativecommons.org/licenses/by/4.0/), which permits unrestricted use, distribution, and reproduction in any medium, provided you give appropriate credit to the original author(s) and the source, provide a link to the Creative Commons license, and indicate if changes were made. The Creative Commons Public Domain Dedication waiver (http://creativecommons.org/publicdomain/zero/1.0/) applies to the data made available in this article, unless otherwise stated. 


\section{Background}

Chromosome rearrangements play a role in species' adaptation and evolution by generating structural genomic variations [1], affecting recombination [2], and changing the pattern of gene expression [3, 4]. Although chromosome rearrangements affect all groups of living organisms, genomes of different lineages have been preferentially shaped by particular types of rearrangements. For example, evolution of angiosperm plants has been accompanied by multiplication of entire chromosome compliment (polyploidization) and subsequent diploidization of their genomes [5]. Chromosome translocations, which transfer a whole or part of a chromosome to another chromosome, have been the predominant mechanisms of karyotype evolution in vertebrates [6]. Paracentric inversions, which flip a chromosomal segment $180^{\circ}$, have been particularly frequent in many dipteran insects, including Drosophila and Anopheles species [7]. However, even different Diptera families display distinct patterns of chromosomal evolution. Karyotypes of flies evolve by centric fissions or fusions, by which chromosome arms are combined or separated from each other affecting the total number of chromosomes [8]. In contrast, karyotypes of Anopheles species have no variations in the number of chromosomes that is always $2 n=6$ [9]. The mechanisms of the observed lineage-specificity in the patterns of genome rearrangements are not well understood.

Another unsolved problem of karyotypic evolution is the forces that preserve or destroy the integrity of individual chromosome elements over time. H. J. Muller proposed that the chromosomes of Drosophila species are represented by a set of six homologous chromosome arms [10] named Muller elements A-F. This nomenclature is used to identify homologous linkage groups among species within the Drosophila genus [8]. Similarly, the term "chromosome elements" has been used to define five chromosomal arms that are homologous across Anopheles species. The chromosomal arms in An. gambiae are named as follows: $\mathrm{X}=$ element 1 (e1), $2 \mathrm{R}=\mathrm{e} 2,2 \mathrm{~L}=\mathrm{e} 3,3 \mathrm{R}=\mathrm{e} 4$, and $3 \mathrm{~L}=\mathrm{e} 5[11,12]$. Chromosome elements of D. melanogaster and An. gambiae have only limited homology indicating that multiple inter-arm rearrangements have been accumulated since the split of the two genera about 250 million years ago (MYA) [13]. The most conserved pair of chromosomal arms, 2L of D. melanogaster (Muller element B) and 3R of An. gambiae (chromosome element 4), share $76 \%$ of the orthologs and $95 \%$ of microsynteny blocks. Physical genome mapping demonstrated that even within genus Drosophila a perfect one-to-one correspondence between the Muller elements and chromosome arms has been occasionally violated by pericentric inversions [8].
A pattern of chromosome rearrangements between $A n$. gambiae and other mosquito species, including $A n$. albimanus, An. atroparvus, An. funestus, An. sinensis, and $A n$. stephensi, has been analyzed using cytogenetic physical maps and partially mapped genome assemblies $[11,12,14-24]$. These studies demonstrated that autosomal arms in Anopheles exchange between chromosomes via whole-arm translocation. In addition, numerous paracentric inversions reshuffle the gene order within chromosome elements. At that time, it was concluded that unlike Drosophila, Anopheles chromosomal arms evolve as intact elements [24]. However, a more recent comparative analysis of nearly complete genome maps of $A n$. albimanus and An. gambiae detected genetic exchanges between chromosome elements 2 and 4 and between chromosome elements 3 and 5 [25]. These data suggest that inter-arm rearrangements occurred since the two subgenera, Nyssorhynchus ( $A n$. albimanus) and Cellia (An. gambiae), diverged about 100 MYA. To obtain more detailed insights into the pattern of these rearrangements, a near-complete genome map of a species that is less diverged from $A n$. gambiae than An. albimanus is needed. A representative of subgenus Anopheles, An. atroparvus, which diverged from species of subgenus Cellia about 58 MYA, can be a suitable candidate for studying inter-arm rearrangements in malaria mosquitoes.

Anopheles atroparvus belongs to the Maculipennis subgroup [26], which also includes $A n$. artemievi, $A n$. beklemishevi, An. daciae, An. labranchiae, An. maculipennis, An. martinius, An. melanoon, An. messeae, An. persiensis, and An. sacharovi. Four species from the Maculipennis subgroup, An. atroparvus, An. labranchiae, $A n$. messeae, and $A n$. sacharovi, are dominant vectors of malaria in Europe and the Middle East [27]. The distribution of $A n$. atroparvus ranges from Great Britain to Europe to North Caucasus in Russia but avoids some Mediterranean regions, such as Southern Italy, Greece, and Turkey. The risk of malaria transmission by An. atroparvus exists in Eastern Spain [28, 29], Portugal [30], South France [31], and England [32]. The epidemiological importance of $A n$. atroparvus stimulated early studies of various aspects of this species' biology, including cytogenetics [33-35]. The first cytogenetic photomap was developed for polytene chromosomes from the salivary glands [36]. This map followed the nomenclature of the drawn cytogenetic maps for other species from the Maculipennis group [37]. Chromosomes were numbered in the order of increasing size. The longer and shorter arms were named as the right and left arms, respectively. Based on the banding patterns, the chromosomes were divided into 39 numbered regions. The banding pattern of the An. atroparvus chromosomes was considered as standard, and the map 
was used to study chromosomal evolution and phylogenetic relationships based on overlapping chromosomal inversions among the Palearctic members of the Maculipennis group [38]. Inversion polymorphism is rarely detected in natural populations of An. atroparvus. For example, only one paracentric inversion on the $3 \mathrm{~L}$ arm was found at low frequency in eastern Europe [38].

The genome of the EBRO strain of An. atroparvus has been sequenced as part of the 16 Anopheles Genomes Project [24]. The An. atroparvus genome assembly was made from 101-bp paired-end Illumina HiSeq2000 reads generated from three libraries: a 180-bp insert "fragment" library, a 1.5-kb "jump" library, and a 38-kb fosmid scale Illumina ("fosill") library. The draft genome assembly of this species consisted of 1371 scaffolds with an N50 scaffold size of 9,206,694 bp and a total assembly size of 224,290,125 bp. The fragmented assembly of $A n$. atroparvus did not allow studies that require chromosome-level genomic data such as the analysis of chromosomal rearrangements. In the effort to anchor genomic scaffolds to chromosomes, a new cytogenetic photomap for ovarian nurse cell chromosomes of $A n$. atroparvus has been developed [21]. This map was constructed from high-resolution phase-contrast digital images of chromosomes, which were straighten to facilitate physical genome mapping. A previous mapping assigned $88.82 \mathrm{Mb}$ of genomic scaffolds to polytene chromosomes, which constitute $\sim 40 \%$ of the An. atroparvus genome assembly [21, 24].

To study the pattern of genomic rearrangements in the genus Anopheles, we upgraded the previously developed cytogenetic map [21] and physically mapped $89.6 \%$ of the An. atroparvus genome assembly to the chromosomes. Our comparative analysis of the An. atroparvus, An. gambiae, and An. albimanus physical genome maps led to the discovery of partial-arm reciprocal translocations. In addition, we characterized the rates of the rearrangements among the species and identified large conserved synteny blocks within chromosomal arms.

\section{Methods}

\section{Mosquito colony maintenance and ovary preservation}

Anopheles atroparvus mosquitoes were obtained from a laboratory colony hosted by Tomsk State University, Russia. The laboratory colony was maintained in the insectary at $27^{\circ} \mathrm{C}$, with a 12 -h cycle of light and darkness. To obtain half-gravid females, mosquitoes were blood fed on defibrinated sheep blood using artificial bloodfeeders. Approximately $30-36 \mathrm{~h}$ post-blood feeding, ovaries were pulled out of abdomens and fixed in Carnoy's solution (3: 1, ethanol: glacial acetic acid by volume). Ovaries were preserved in the fixative solution from 24 h up to 1 month at $-20^{\circ} \mathrm{C}$.

\section{Chromosome preparation}

A single ovary from one pair was used for one preparation of ovarian nurse cell chromosomes. Ovaries were held for $5 \mathrm{~min}$ in a drop of $50 \%$ propionic acid, where they were macerated and squashed on a slide. The quality of preparations was checked under an AxioImager A1 microscope (Carl Zeiss, OPTEC LLC, Novosibirsk, Russia). High-quality preparations were then flashfrozen in liquid nitrogen. After removing coverslips, preparations were dehydrated in an ethanol series (50, 70 , and $96 \%$ ), air-dried, and stored for up to 3 months at room temperature.

\section{Cytogenetic map upgrade}

Chromosome images were observed using a phase-contrast AxioImager A1 microscope with an attached CCD camera MRc5 using AxioVision Version 4.7.1 software (Carl Zeiss, OPTEC LLC, Novosibirsk, Russia). Images were combined, straightened, shaped, and cropped using Adobe Photoshop CS as described elsewhere [39]. Most of the chromosome images, arm naming, and borders of divisions and subdivisions were taken from the published cytogenetic map [21]. New improved images were incorporated into some subtelomeric and pericentromeric regions, and a reverse order of lettered subdivisions was used for arms $2 \mathrm{~L}$ and $3 \mathrm{~L}$.

\section{Probe preparation and fluorescence in situ hybridization} Gene-specific primers were designed to amplify unique exon sequences from the beginning and end of each scaffold using PRIMER-BLAST software available at NCBI (http://www.ncbi.nlm.nih.gov/tools/primer-blast/). The primer design was based on gene annotations from the AatrE1 genome assembly available at VectorBase (https://www.vectorbase.org/organisms/anopheles-atroparvus/ebro/aatre1). Polymerase chain reaction (PCR) was performed in the presence of a $1 \times$ PCR buffer (SibEnzyme Ltd., Novosibirsk, Russia), $2.5 \mathrm{mM} \mathrm{MgCl}_{2}$ (SibEnzyme Ltd., Novosibirsk, Russia), $0.2 \mathrm{mM}$ dNTP (Thermo Fisher Scientific, Waltham, MA, USA), and 0. $02 \mathrm{u} / \mu \mathrm{l}$ Taq Polymerase (SibEnzyme Ltd., Novosibirsk, Russia). Amplified fragments were labeled using random primers. $25 \mu \mathrm{l}$ of labelling reaction contained $50 \mathrm{ng}$ of DNA, 1× Klenow buffer (Thermo Fisher Scientific, Waltham, MA, USA), $44 \mathrm{ng} / \mu \mathrm{l}$ Exo-Resistant Random Primer (Thermo Fisher Scientific, Waltham, MA, USA) $0.1 \mathrm{mM}$ dATP, dGTP, dCTP and $0.015 \mathrm{mM}$ dTTP, 0 . 016 mM TAMRA-5-dUTP or Biotin-11-dUTP (Biosan, Novosibirsk, Russia), and 5 u Klenow fragment (Thermo Fisher Scientific, Waltham, MA, USA). The required amounts of DNA, Klenow buffer, and Random Primer were mixed, brought up to $12 \mu \mathrm{l}$ with water, and heated to $95{ }^{\circ} \mathrm{C}$ for $5 \mathrm{~min}$ in a thermocycler. The solution was chilled on ice, and appropriate amounts of nucleotides, Klenow fragment, and water were added to the final 
volume of $25 \mu \mathrm{l}$. The reaction mixture was incubated at $37{ }^{\circ} \mathrm{C}$ for $18 \mathrm{~h}$. Fluorescence in situ hybridization (FISH) was performed using a previously described standard protocol [39]. Biotin-labelled DNA probes were detected by Avidin conjugated with FITC (Sigma-Aldrich, St. Louis, MO, USA) diluted 1:100 with blocking solution (1\% Bovine Serum Albumin (Sigma-Aldrich, St. Louis, MO, USA), $1 \times$ PBS with $0.1 \%$ Tween-20) for $30 \mathrm{~min}$ at $37{ }^{\circ} \mathrm{C}$. The rest of the unbound detector was washed with $1 \times$ PBS with $0,1 \%$ Tween-20 three times for $5 \mathrm{~min}$ each at room temperature. Overall chromosome painting was performed by DAPI in the antifade mounting medium Vectashield (Vector Laboratories, Inc., Burlingame, CA, USA).

\section{Synteny-based scaffolds adjacencies}

Several potential scaffold adjacencies with no gaps were identified during physical mapping. For "gluing" $A n$. atroparvus genomic scaffolds, several dozen genes from the candidate scaffolds' ends were selected. Orthologous genes for these genes in the An. gambiae and An. albimanus genomes were identified using BioMart (http:// biomart.vectorbase.org/biomart/martview/). If orthologs for all An. atroparvus genes from candidate scaffolds' ends were located continuously in single scaffolds of $A n$. gambiae and An. albimanus, An. atroparvus scaffolds were considered adjacent to each other without gaps.

\section{Identification of conserved synteny blocks and rearrangements}

The BioMart service (http://biomart.vectorbase.org/biomart/martview/) was used to extract the set of all annotated orthologous genes for An. atroparvus (AatrE1 genome assembly v.86.1), An. albimanus (AalbS2 genome assembly v.86.2), and An. gambiae (AgamP4 genome assembly v.86.4). These data were prepared using $\mathrm{R}$ and RStudio IDE to generate an input file for GRIMMSynteny v. 2.02 [40]. During the preparation of the data, coordinates of the $A n$. atroparvus genes within genomic scaffolds were converted into coordinates on the An. atroparvus chromosomes. GRIMM-Synteny takes coordinates of orthologous genes of species and forms syntenic blocks based on specified parameters, such as minimum block size and gap threshold (a maximum distance between genes in a synteny block). Synteny blocks obtained by GRIMM-Synteny were visualized using genoPlotR [41]. The Multiple Genome Rearrangement (MGR) program [42] was used to determine the number and types of rearrangements that caused the synteny block reshuffling among three species. To run the random model for synteny blocks, we obtained the sample of random breaks by generating $(N-1) * 2$ random numbers from 0 to $M$, where $N$ and $M$ are a mean number of synteny blocks and a mean length of genomes (base pairs) in three species, respectively. We arranged all coordinates of random breaks ascending and measured the length between each break. To simulate random distances between synteny blocks, we randomly removed one half of the samples. Eventually, we obtained a sample of lengths for $N$ random synteny blocks.

\section{Results}

\section{An upgraded map for ovarian nurse cell polytene} chromosomes of An. atroparvus

The polytene chromosome complement of An. atroparvus consists of five arms: X, 2R, 2L, 3R, and 3L. The karyotype from female ovarian nurse cells is represented by the smallest sex chromosome $\mathrm{X}$, intermediate metacentric chromosome 2, and the largest submetacentric chromosome 3 (Table 1). We observed no polymorphic inversions in the laboratory strain of An. atroparvus.

Here we upgraded our previously published highresolution chromosome map for $A n$. atroparvus from ovarian nurse cells [21]. We replaced subtelomeric and pericetromeric regions of arms $2 \mathrm{~L}$ and $2 \mathrm{R}$ with images that have more distinct, clear banding patterns. The previous map had the order of numbered divisions and lettered subdivisions on the left arms of autosomes in the opposite order. This system was inherited from the older map [36], but it was not convenient for the genome mapping. Therefore, we reversed the order of lettered subdivisions in chromosome arms 2L and 3L (Fig. 1).

\section{A physical map for the An. atroparvus genome}

In this study, we physically mapped 39 genomic scaffolds to polytene chromosomes of An. atroparvus using FISH of gene probes (Fig. 1). Positions and adjacencies of 10 additional scaffolds were predicted based on synteny information; nine of them were also oriented. Together with previously mapped seven scaffolds [21, 24], a total of 56 scaffolds have been anchored to the An. atroparvus chromosomes (Additional file 1: Table S1). The mapped scaffolds constitute $200,912,972$ bp or $89.6 \%$ of the total An. atroparvus genome assembly. To orient scaffolds using FISH, two genes, one from the beginning of the scaffold and the other from the end of the scaffold, were labeled by fluorescent dyes of different colors and hybridized to polytene chromosomes simultaneously (Fig. 2). Probes from the same genomic scaffolds were

Table 1 Measurements of An. atroparvus ovarian nurse cells polytene chromosomes

\begin{tabular}{llll}
\hline Parameter & Chromosome X & Chromosome 2 & Chromosome 3 \\
\hline Average length, $\mu \mathrm{m}$ & 131.4 & 713.1 & 757.4 \\
Relative length, \% & 8.3 & 44.4 & 47.3 \\
$\begin{array}{l}\text { Centromere } \\
\text { index, \% }\end{array}$ & 0.0 & 46.0 & 38.4 \\
\hline
\end{tabular}



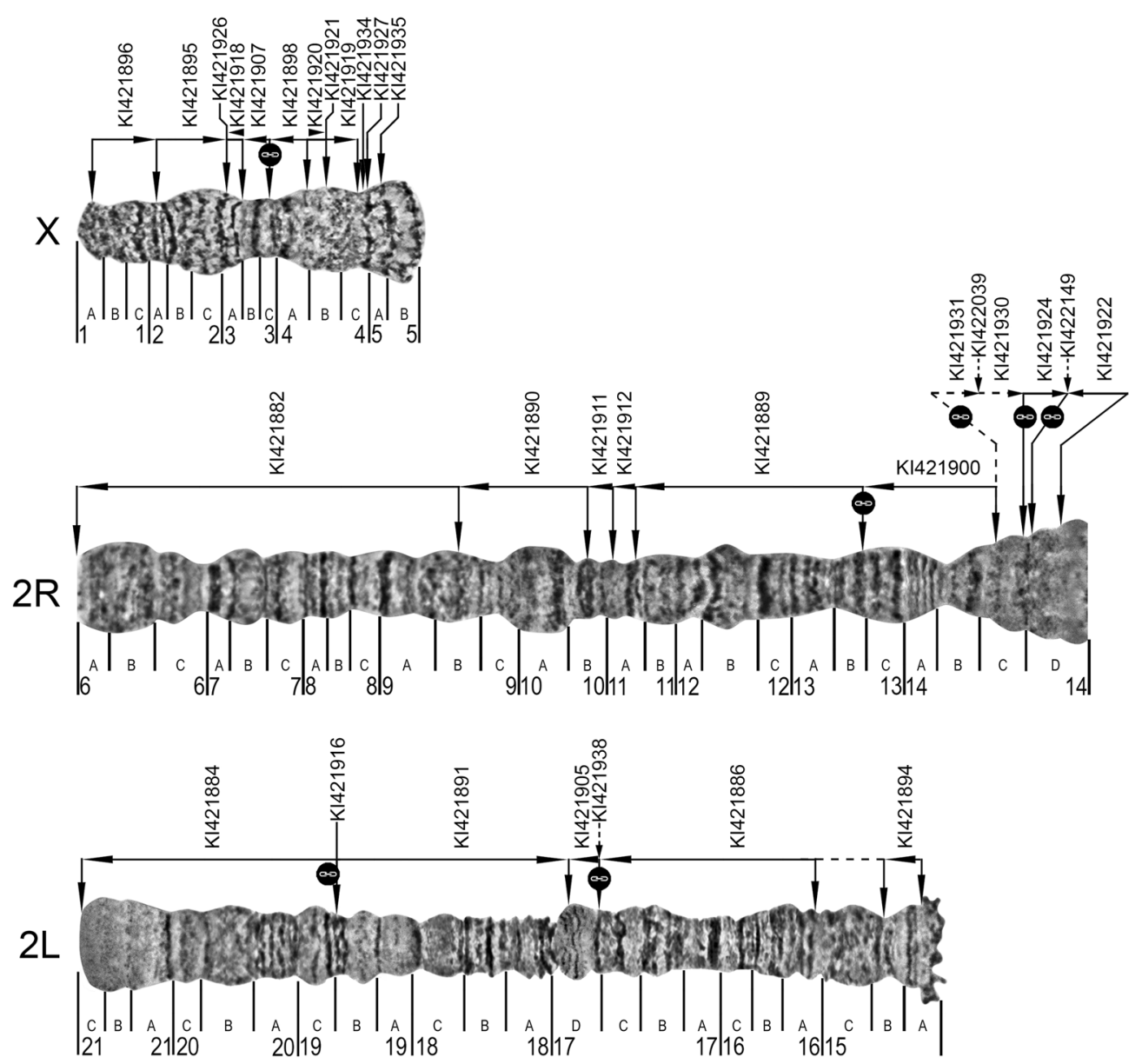

$2 \mathrm{R}$
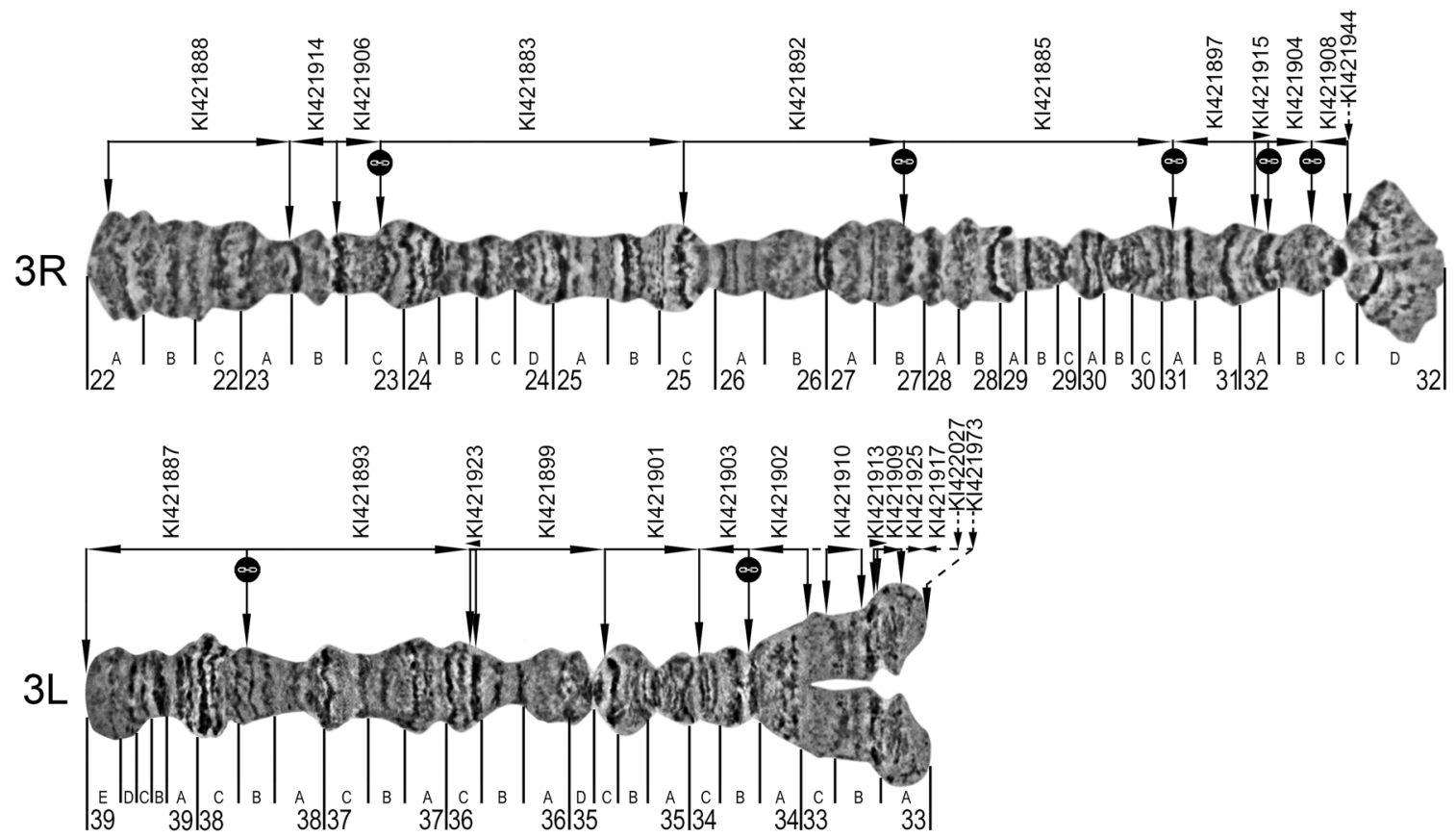

Fig. 1 (See legend on next page.) 
(See figure on previous page.)

Fig. 1 A high-resolution cytogenetic map and physical genome map for An. atroparvus. Numbered divisions and lettered subdivisions are shown below the chromosome images. Horizontal lines and arrows indicate the order and orientation of genomic scaffolds. The names of genomic scaffolds are shown above horizontal lines. The start and end positions of the genomic scaffolds are shown by vertical arrows corresponding to mapped FISH probes. The dashed horizontal line in 2L:15B-16A indicates a predicted adjacency of scaffolds KI421884 and KI421886. The "link" signs mark the scaffolds' adjacencies inferred from the analysis of synteny

found only on the same chromosome arms, suggesting that there are no sequence misassemblies in the $A n$. atroparvus genome. All probes produced clear, unique signals, and they were successfully placed onto the cytogenetic map based on the banding patterns (Fig. 1). We considered neighboring scaffolds adjacent if two FISH probes from different scaffolds hybridized to the same site on chromosomes (Additional file 2: Table S2). Our analysis of conserved synteny between genomes of $A n$. atroparvus and both An. albimanus and An. gambiae also helped to juxtapose pairs of scaffolds and link them together without cytogeneic gaps. For instance, we "glued" five pairs of scaffolds on the 3R arm. Also, small gaps in regions $14 \mathrm{C}$ of the $2 \mathrm{R}$ arm, $32 \mathrm{C}$ of the $3 \mathrm{R}$ arm, and $33 \mathrm{~B}$ of the $3 \mathrm{~L}$ arm were filled by small scaffolds based on the synteny information (Fig. 1). The remaining unmapped 1315 scaffolds make up $23,377,153$ bp or $10.4 \%$ of the total genome assembly.
The unmapped portion of the genome is expected to be distributed throughout the regions of pericentromeric and intercalary heterochromatin, which have no clear banding pattern. For example, the pericentromeric heterochromatin in region $5 \mathrm{~B}$ of the $\mathrm{X}$ chromosome and region $32 \mathrm{D}$ of the $3 \mathrm{R}$ arm, as well as the intercalary heterochromatin in region $15 \mathrm{~B}-16 \mathrm{~A}$ of the $2 \mathrm{~L}$ arm, remain uncovered by the genomic scaffolds.

\section{Chromosome arm comparison and inter-arm rearrangements}

To identify chromosomal rearrangements in malaria mosquitoes, the genome of An. atroparvus was aligned against the chromosomally-anchored genome assemblies of An. gambiae and An. albimanus [25, 39, 43]. We used GRIMM-Synteny to identify conserved synteny blocks shared among the three species. Our parameters for the algorithm required at least two orthologous genes within
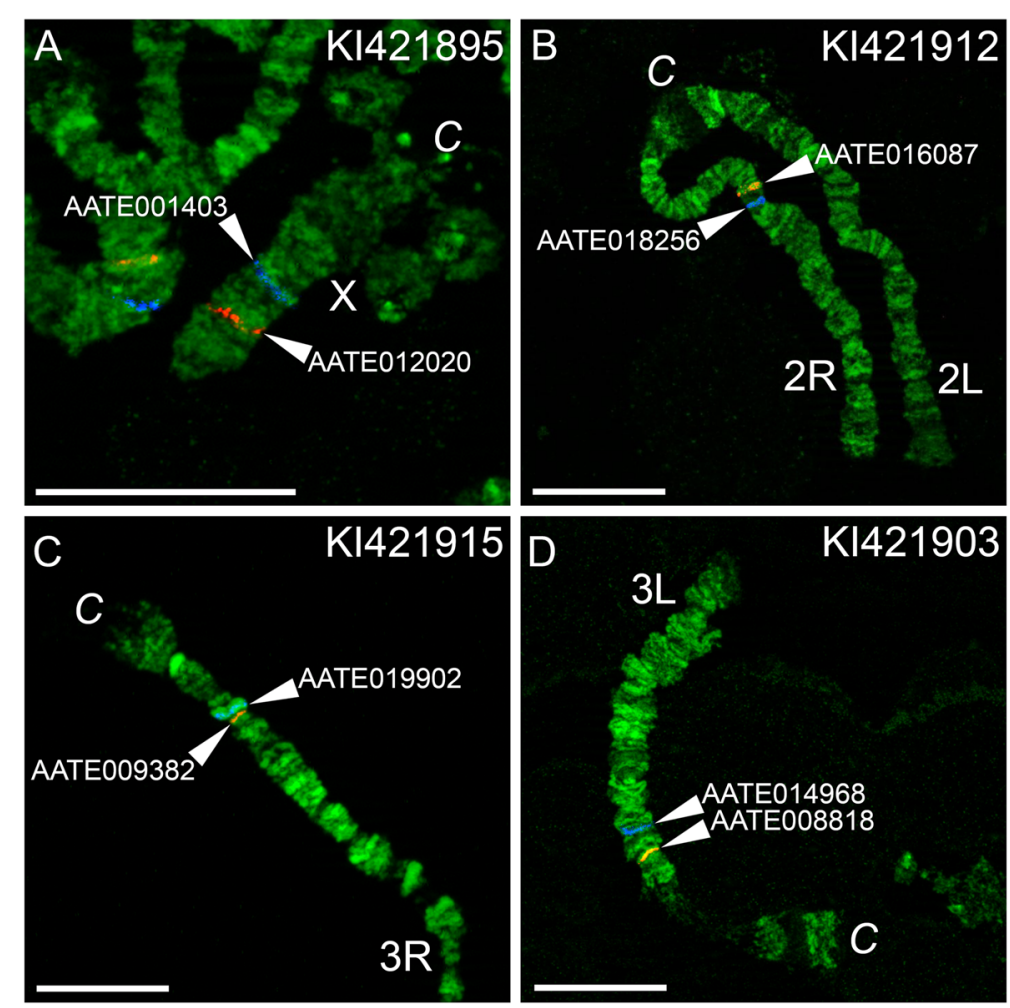

Fig. 2 Physical mapping of genomic scaffolds to An. atroparvus chromosomes by FISH. The positions of the red and blue signals show the beginning and the end of the genomic scaffolds KI421895 (a), KI421912 (b), KI421915 (c), and KI421903 (d) on chromosomes X, 2R, 3R, and $3 L$, respectively 

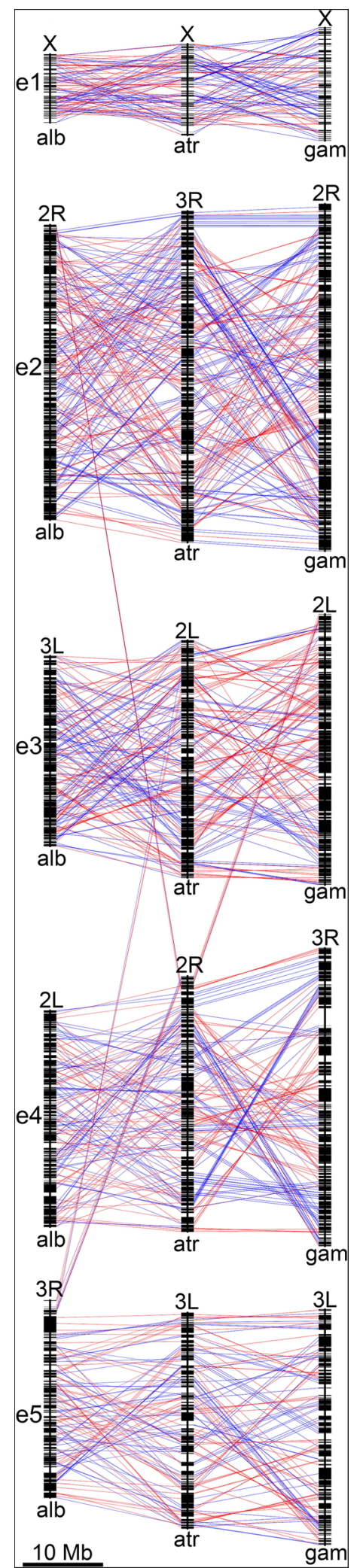

Fig. 3 A plot of genome rearrangement among three species of Anopheles. Five chromosomal arms of An. albimanus (alb), An. atroparvus (atr), and An. gambiae (gam) are shown. Chromosome elements are labeled as e1 - e5. Black rectangles along the chromosomes represent conserved synteny blocks. Blocks conserved among species are connected by blue lines if they are in the same orientation and by red lines if they are in reverse orientation relative to An. atroparvus blocks, which were chosen as standard. Centromeres are on the top of each element. The pericentromeric region of the An. atroparvus $2 \mathrm{R}$ arm (e4) exchanged genomic material with e2, e3, and e5, and the pericentromeric region of the An. atroparvus $2 \mathrm{~L}$ (e3) exchanged genomic material with e5 of other species during evolution of Anopheles

a synteny block (in order to exclude single-gene transpositions) and the gap size, which is a maximum distance between genes within a synteny block, equal to $115 \mathrm{~kb}$. We identified conserved synteny blocks of average length equal to $143 \mathrm{~kb}$, which is in agreement with the previous study [24]. We consider chromosomal arms as elements that are homologous across all species $[11,12]$. We found that the majority of the orthologous genes are located on the same chromosome element across species, although in a different order. Likewise, the majority of rearrangements takes place within the chromosomal arm, but several exceptions are apparent. The pericentromeric region of e4 in An. atroparvus (arm 2R) contains several synteny blocks that correspond to e2 (2R), e3 (3L), e5 (3R) of An. albimanus, and e3 (2L) of An. gambiae. Also, the pericentromeric region of e3 in An. atroparvus (arm 2L) contains synteny blocks that correspond to e5 (3R) of An. albimanus (Fig. 3).

To investigate the syntenic relationships between chromosome elements of different species, we identified synteny blocks in the pericentromeric regions by BLAST. If paracentric inversions are ignored, nine major synteny blocks can be identified among An. atroparvus, An. gambiae, and An. albimanus. Five of these blocks changed their chromosome element position during evolution (Additional file 3: Table S3). The centromere position with respect to some of these blocks changes among species indicating inter-arm rearrangements (Fig. 4). We calculated the numbers and determined types of rearrangements between chromosome elements using the MGR program [42], which uses the same algorithm as GRIMM. The following orders and orientations of conserved blocks were used as an input for the MGR run, where the symbol \$ indicates the end of each chromosome element.

$>$ An. gambiae

$1 \$ 23456 \$ 78 \$ 9 \$$

$>$ An. atroparvus

-1 \$ -9 \$ 6-4 -5 \$ - $2-3-87$ \$

$>$ An. albimanus 


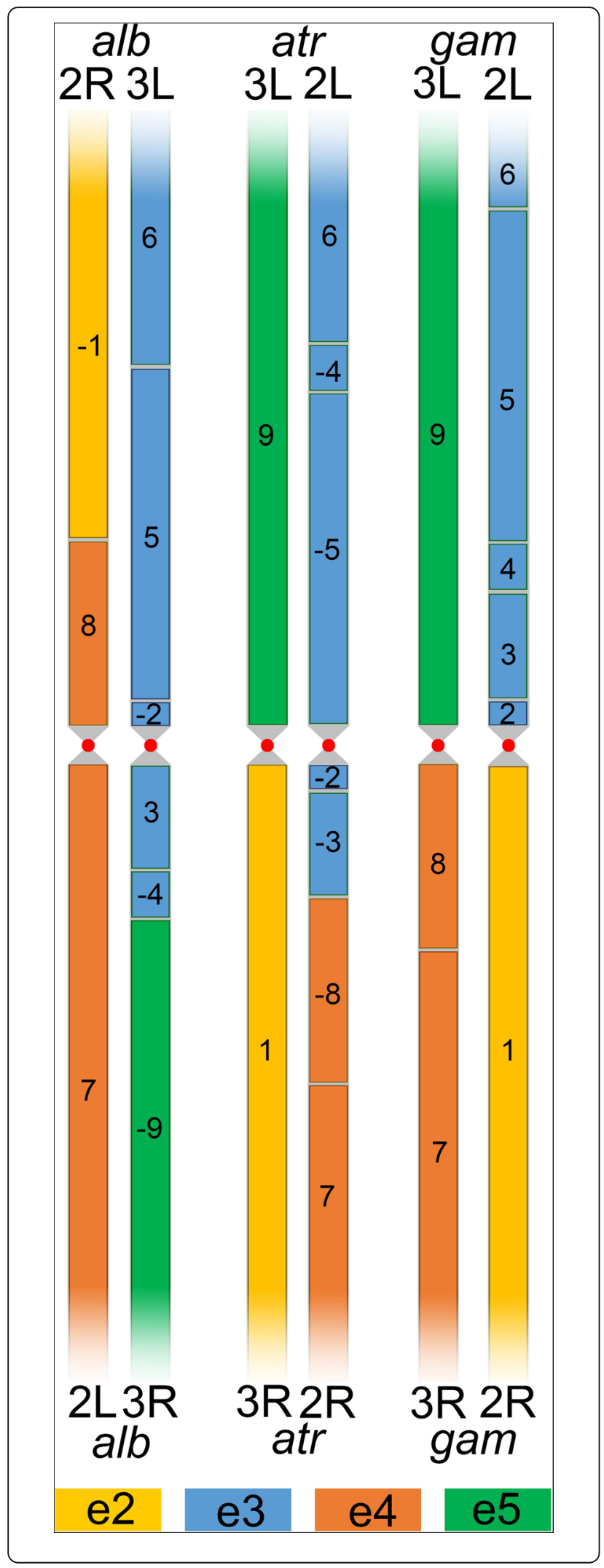

Fig. 4 A scheme of distribution of nine major conserved synteny blocks in the pericentromeric regions of the autosomes of $A n$. atroparvus (atr), An. albimanus (alb), and An. gambiae (gam). Centromeres are represented by red circles. The lengths of synteny blocks are not in scale

\section{$-18 \$ 7 \$ 65-2 \$ 3-4-9 \$$}

The MGR program reconstructs a putative ancestral karyotype, determines the types of rearrangements, creates a phylogenetic tree, and implements an algorithm that minimizes the sum of the rearrangements over all edges of the phylogenetic tree (Additional file 4: Figure S1A). Accordingly, the An. gambiae elements have a close resemblance with the putative ancestral karyotype, as they differ by only three paracentric inversions and have a whole-arm synteny preservation (Additional file 4: Figure S1B). In contrast, the An. atroparvus chromosomes differ from the ancestral karyotype by two partial-arm translocations and one paracentric inversion (Additional file 4: Figure S1C), while the An. albimanus accumulated three partial-arm translocations and one paracentric inversion after the divergence from the ancestral species (Additional file 4: Figure S1D). In pair-wise comparisons, An. gambiae and An. atroparvus differ by two partial-arm translocations and three paracentric inversions (Additional file 4: Figure S1E), An. gambiae and An. albimanus differ by three partial-arm translocations and three paracentric inversions (Additional file 4: Figure S1F), while An. atroparvus and An. albimanus differ by five partial-arm translocations and one paracentric inversion (Additional file 4: Figure S1G).

The lengths of the conserved synteny blocks involved in partial-arm translocations and immediately adjacent to the centromeres vary from 5031 bp (block 2 in $A n$. albimanus) to 2,546,887 bp (block 5 in An. atroparvus) (Additional file 3: Table S3). This means that breakpoints of partial-arm translocations occurred in close proximity to the centromere. However, genes of some blocks, which changed their chromosome element position during evolution, can also be found far away from the centromere: $9.8 \mathrm{Mb}$ in An. gambiae and $13.8 \mathrm{Mb}$ in An. albimanus. This observation suggests that paracentric inversions moved the genes along chromosomal arms after the partial-arm translocations occurred.

\section{Conserved synteny blocks in genus Anopheles}

We calculated the number of conserved synteny blocks for every chromosome element of An. albimanus, An. atroparvus, and An. gambiae in pairwise comparisons (Table 2). The number of synteny blocks corresponds with phylogenetic relations between the three species [24]. Accordingly, the smallest number of synteny blocks was observed between An. atroparvus and An. gambiae, which have the shortest divergence time of about 58 
Table 2 Numbers of conserved synteny blocks in pairwise comparisons of An. albimanus, An. gambiae, and An. atroparvus

\begin{tabular}{lllllll}
\hline Species compared & $\mathrm{e} 1$ & $\mathrm{e} 2$ & $\mathrm{e} 3$ & $\mathrm{e} 4$ & $\mathrm{e} 5$ & Total number of blocks \\
\hline An. albimanus / An. gambiae & 137 & 159 & 114 & 97 & 79 & 586 \\
An. atroparvus / An. albimanus & 105 & 132 & 66 & 85 & 52 & 440 \\
An. atroparvus / An. gambiae & 94 & 78 & 43 & 37 & 34 & 286 \\
\hline
\end{tabular}

MYA. In agreement with previous studies [15, 23, 24], we observed enrichment of the number of conserved synteny blocks in the X chromosome (e1) (Table 2), which comprises only $8.3 \%$ of the total chromosome length, compared with autosomes (Table 1).

We identified and localized the largest conserved synteny blocks in pairwise comparisons of autosomes, An. albimanus: An. atroparvus and An. atroparvus: An. gambiae, each time excluding the third species from the comparison (Fig. 5). This analysis demonstrated how large conserved blocks are distributed along the chromosome length. It was clear that in most cases the largest synteny blocks avoided being in the middle of the chromosomal arms, except e2 of An. atroparvus and An. gambiae. A similar trend was observed in a three-species comparison, An. albimanus: An. atroparvus: An. gambiae. Out of the 24 largest blocks, 17 are located either in the first (telomeric) or in the last (centromeric) quadrants of the chromosome arms. Only 7 of the largest blocks are located in the two middle quadrants of the chromosome arms (Fig. 6). As expected, lengths of the largest conserved synteny blocks are smaller than that in pair-wise comparisons (Table 3).

Our simulation shows that these blocks cannot exist under a random breakage model (Fig. 7). Therefore, they are likely the result of functional or structural constraints to breakage.

\section{Rates of inversion fixation in malaria mosquitoes}

Using the GRIMM-Synteny program [44], we calculated the number of fixed inversions in each chromosome element between $A n$. atroparvus, An. gambiae, An. albimanus, and the putative ancestral Anopheles species (Table 4). As in the case with the number of conserved synteny blocks (Table 2), we observed enrichment of rearrangements in the $\mathrm{X}$ chromosome (e1) compared with autosomes.

We also calculated the minimum number of paracentric inversions in pair-wise comparisons of An. atroparvus, An. gambiae, and An. albimanus. The number of inversions between $A n$. atroparvus and An. gambiae was less than the number of inversions between An. atroparvus and An. albimanus, which is in concordance with their phylogenetic relations [24]. To calculate the number of rearrangements/Mb/MY for these species, we used the average length of the mapped portion of the genome assembly to each chromosomal arm of a particular pair of species and the divergence time between them. In all species pairs, the gene order on the $\mathrm{X}$ chromosome (e1) evolved faster than that on the autosomes (Table 5).

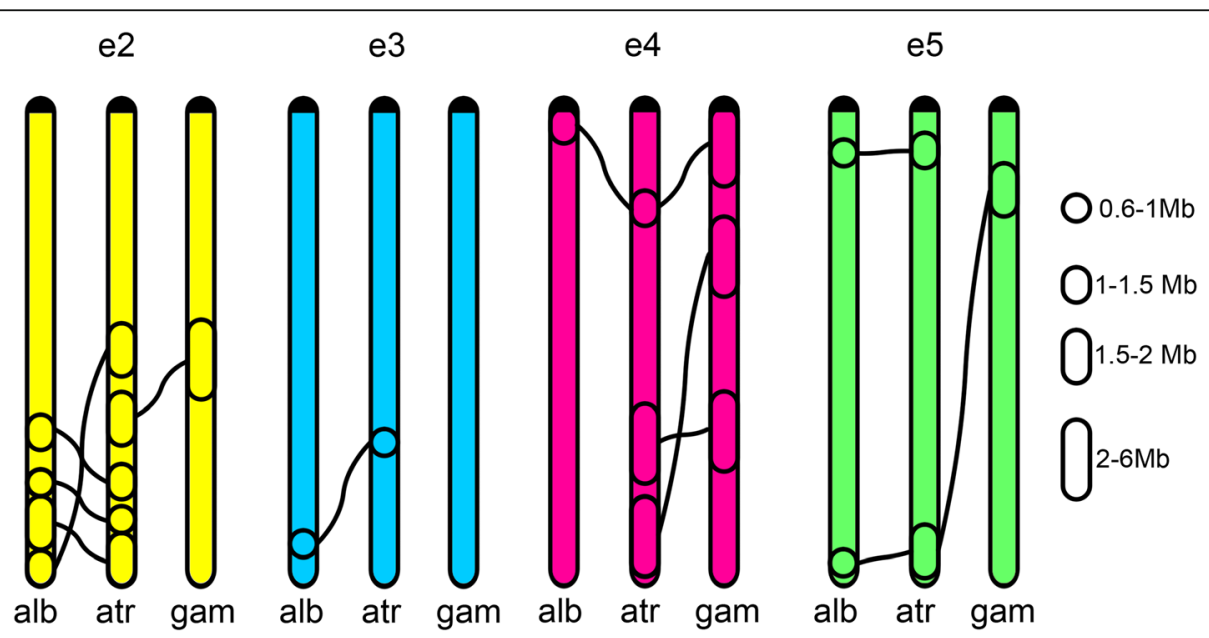

Fig. 5 Distribution of the largest conserved synteny blocks in pair-wise comparison within the autosomal elements e2-e5. The dark caps on the top of the arms represent centromeres alb - An. albimanus, atr - An. atroparvus, and gam - An. gambiae 


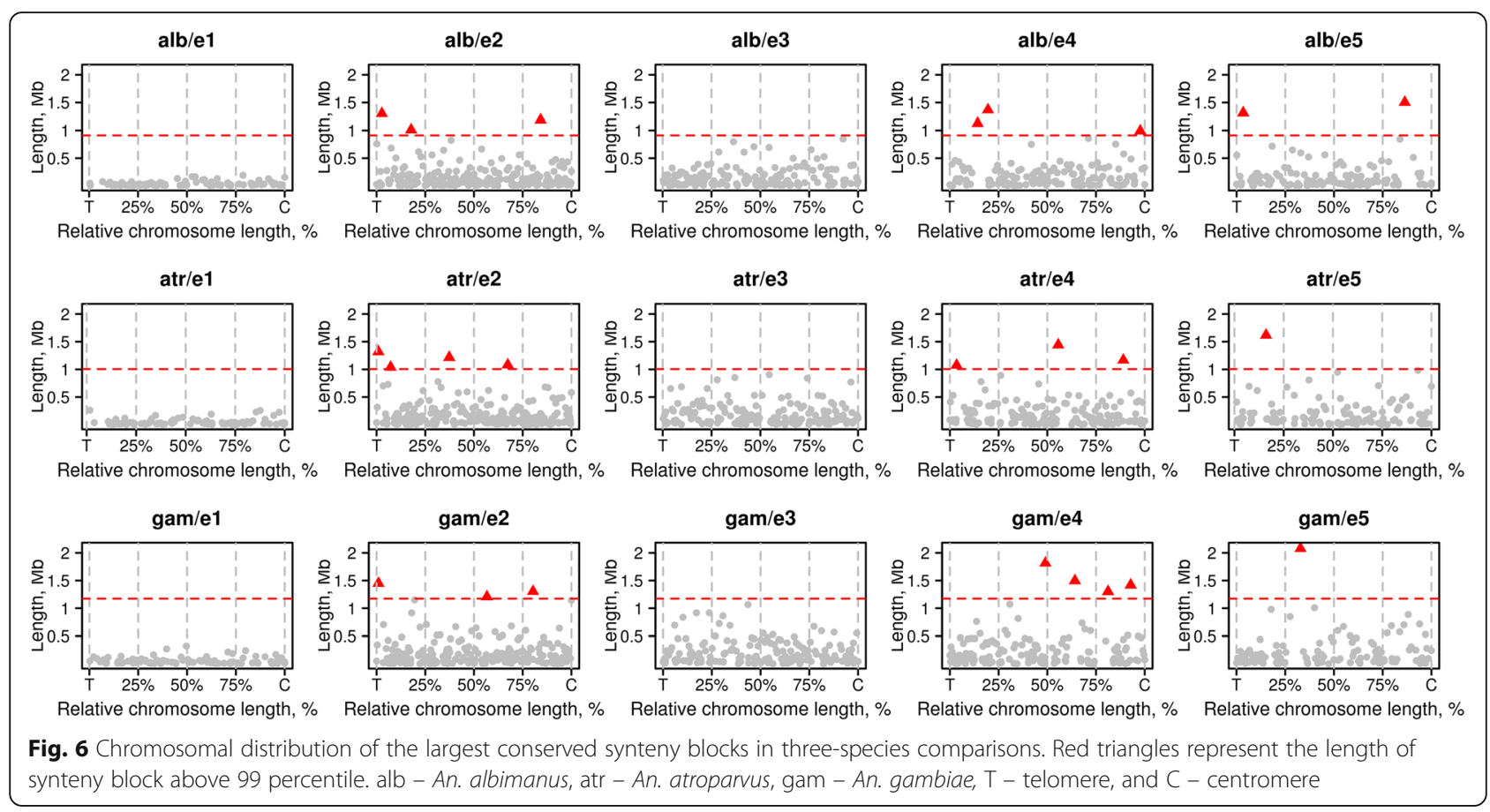

\section{Discussion}

Comparison of the An. atroparvus genome map with mapped assemblies of other anophelines

In this study, we developed a detailed physical map of the $A n$. atroparvus genome with $89.6 \%$ of the sequenced assembly anchored to chromosomes (Fig. 1, Additional file 1: Table S1). After An. albimanus, the An. atroparvus genome has the second genome mapping coverage among Anophelinae genome assemblies (Table 6). The recently developed AalbS2 genome assembly has $98.2 \%$ of the total genome mapped to the An. albimanus chromosomes

(https://www.vectorbase.org/organisms/anopheles-albimanus/stecla) [25]. For comparison, the physically mapped portion of the An. gambiae AgamP4 assembly is equal to $84.3 \%$ of the total sequenced genome [39, 43]. However, An. gambiae has the highest density of chromosomally mapped DNA markers among mosquitoes. The An. stephensi AsteI2 [14], An. sinensis AsinC2 [23], and An. funestus AfunF1 [24] assemblies have 62, 35.9, and $35.1 \%$ of their genomes mapped chromosomes, respectively. A relatively high coverage of the physical map

Table 3 Lengths of the largest conserved synteny blocks in a three-species comparison among An. atroparvus, An. gambiae, and An. albimanus

\begin{tabular}{llll}
\hline Species & $\begin{array}{l}\text { Minimum length of } \\
\text { blocks from the } 99 \\
\text { percentile }\end{array}$ & $\begin{array}{l}\text { Mean length of } \\
\text { the largest } \\
\text { synteny blocks }\end{array}$ & $\begin{array}{l}\text { Maximum length } \\
\text { of the largest } \\
\text { synteny blocks }\end{array}$ \\
\hline An. albimanus & 911,714 & $1,226,232$ & $1,504,168$ \\
An. atroparvus & $1,005,254$ & $1,245,690$ & $1,618,976$ \\
An. gambiae & $1,173,026$ & $1,509,795$ & $2,078,641$ \\
\hline
\end{tabular}

for An. atroparvus was achieved due to the good quality of the genome assembly. The AatrE1 genome assembly consists of 1371 scaffolds with an N50 scaffold size of 9 . $2 \mathrm{Mb}$ (https://www.vectorbase.org/organisms/anophelesatroparvus/ebro/aatre1). This N50 scaffold size is still twice less than the N50 size of $18.1 \mathrm{Mb}$ for An. albimanus but much higher than the N50 sizes of $1.6 \mathrm{Mb}$ for An. stephensi, $814 \mathrm{~kb}$ for An. sinensis, or $672 \mathrm{~kb}$ for $A n$. funestus. Unlike in An. albimanus, our physical mapping did not detect any scaffold misassemblies in $A n$. atroparvus.

\section{The pattern of chromosome rearrangements in malaria mosquitoes}

We used the physical map developed for An. atroparvus in this study to analyze the chromosome rearrangements in the genus Anopheles. The analysis has shown that some pericentromeric regions of chromosome arms $2 \mathrm{R}$ (e4) of An. atroparvus are homologous to portions of arms 2R (e2), 3L (e3), and 3R (e5) of An. albimanus, and to 2L (e3) of An. gambiae (Figs. 3 and 4). This observation violates the previously accepted notion of the whole-arm synteny preservation in the evolution of malaria mosquitoes [11, 12, 14-24]. Our recent study identified the first case of genomic exchanges between chromosome elements that happened during the split of the An. albimanus and An. gambiae lineages [25]. Here, the detailed analysis of rearrangements among $A n$. atroparvus, An. albimanus, and An. gambiae using the MGR program demonstrated that autosomal elements exchange their genetic material via multiple partial-arm 


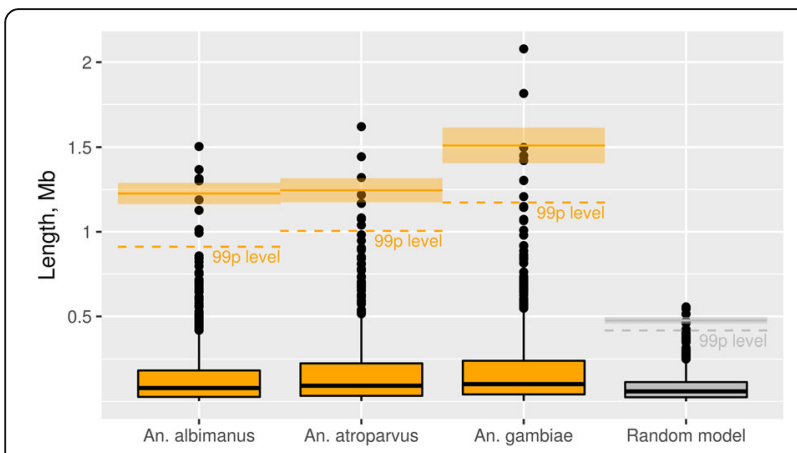

Fig. 7 Observed lengths of synteny blocks in An. albimanus, An. atroparvus, and An. gambiae and calculated lengths of synteny blocks under the random breakage model. Dashed orange and grey lines indicate 99 percentiles in each sample. Solid-orange and-grey rectangles below the 99-percentile level denote the mean lengths of the synteny blocks. Translucent- orange and-grey rectangles above the 99-percentile level denote the standard error of the mean for the lengths of the large synteny blocks

translocations. However, cases of arm integrity preservation were also found in the evolution of malaria mosquitoes. For example, elements 2 and 5 of An. gambiae and $A n$. atroparvus are fully syntenic, and they changed their associations within chromosomes via whole-arm translocations (Fig. 4). Moreover, all chromosome elements of $A n$. gambiae are fully syntenic with chromosome elements of the putative ancestral Anopheles karyotype. Our previous comparative genomic analysis between $A n$. gambiae and $A n$. stephensi indicated that the whole-arm synteny is preserved between these two representatives of subgenus Cellia [14]. Our present study suggests that the integrity of ancestral chromosome elements was broken in subgenera Anopheles and Nyssorhynchus, but not in Cellia. This observation may point to the existence of structural or functional lineage-specific constraints to karyotype evolution in subgenus Cellia.

This study demonstrates distinct features of karyotype evolution in anopheline mosquitoes if compared with fruit flies. The diploid number of chromosomes can change in the evolution of the genus Drosophila, as they can undergo centric fission or fusion. For example, Muller element $\mathrm{F}$ has fused to Muller $\mathrm{E}$ in $D$. willistoni $[45,46]$. Also, Muller element D fused with Muller A to become X-linked in D. pseudoobscura [46, 47]. The

Table 4 Fixed inversions between An. atroparvus, An. gambiae, An. albimanus, and the putative ancestral Anopheles species

\begin{tabular}{lllllll}
\hline Species & $\mathrm{e} 1$ & $\mathrm{e} 2$ & $\mathrm{e} 3$ & $\mathrm{e} 4$ & $\mathrm{e} 5$ & Total \\
\hline An. gambiae & 65 & 62 & 47 & 30 & 33 & 139 \\
An. atroparvus & 32 & 27 & 15 & 19 & 10 & 61 \\
An. albimanus & 70 & 104 & 75 & 77 & 49 & 256 \\
\hline
\end{tabular}

integrity of Muller elements can be broken by pericentric inversions. A pericentric inversion has shuffled genes between Muller elements A and D in D. pseudoobscura and D. persimilis [8, 47]. A shared pericentric inversion has occurred between Muller B and C in D. erecta and D. yakuba [48, 49]. In contrast, the diploid number of chromosomes is always three in Anopheles, but autosomal arm associations changed multiple times during mosquito evolution. The integrity of chromosome elements can be broken by partial-arm translocations. However, unlike Drosophila, the sex chromosome (e1) of malaria mosquitoes does not exchange or merge its genetic material with autosomes via translocations. However, gene retrotransposition rates from the $\mathrm{X}$ chromosome to autosomes even exceed those in fruit flies [24]. Still, the common feature of chromosome evolution shared between mosquitoes and flies is the abundance of paracentric inversions.

\section{The rate of chromosome rearrangements in malaria mosquitoes}

Our GRIMM analysis of paracentric inversions reaffirms the phylogenetic relationships among mosquito lineages. The An. albimanus lineage is one of the earliest radiations within genus Anopheles, which happened about 100 MYA, while An. atroparvus and An. gambiae were part of the same lineage until 58 MYA [24, 50]. We found that the number of conserved synteny blocks between $A n$. atroparvus and An. gambiae was 1.5-2 times smaller than the number of conserved synteny blocks between either $A n$. atroparvus or An. gambiae and $A n$. albimanus (Table 2). The obtained values of rearrangement rates between $A n$. atroparvus and $A n$. gambiae or An. albimanus and An. gambiae were generally lower than those estimated in a previous study [24]. This difference can be explained by the larger portion of the mapped genome in An. albimanus [25] and An. atroparvus used in this study. Our study confirmed previous observations $[15,23,24]$ that the $\mathrm{X}$ chromosome has higher rates of rearrangement than do autosomes (Table 5). The phenomenon of the rapid fixation of $\mathrm{X}$ chromosome rearrangements could indicate that inversions on the $\mathrm{X}$ chromosome are underdominant when in heterozygote, as was theoretically predicted earlier [51].

Despite intensive reshuffling of the chromosomal segments during the evolution of malaria mosquitoes (Fig. 3), certain forces maintain long linkages of genes. Our simulation suggests that large conserved synteny blocks could not be preserved in evolution if breakpoints are randomly distributed along the chromosomes (Fig. 7). Instead, functional or structural constraints to breakage are likely responsible for the preservation of these blocks. The adjacent groups of genes could be resistant to breakage due to co-regulation of gene expression, co-adaptation, 
Table 5 Rearrangement per Mb per MY between pairs of species for each chromosome element

\begin{tabular}{llllllllll}
\hline Species pairs & $\begin{array}{l}\text { Number of } \\
\text { rearrangements }\end{array}$ & $\begin{array}{l}\text { Average length of } \\
\text { the genome assembly }\end{array}$ & $\begin{array}{l}\text { Divergence, } \\
\text { MY }\end{array}$ & e1 & e2 & e3 & e4 & $\begin{array}{l}\text { e5 } \\
\text { Genome } \\
\text { average }\end{array}$ \\
\hline An. atroparvus / An. gambiae & 309 & $248,699,585$ & 58 & 0.077 & 0.025 & 0.026 & 0.019 & 0.020 & 0.043 \\
An. atroparvus / An. albimanus & 465 & $198,814,682$ & 100 & 0.056 & 0.022 & 0.022 & 0.021 & 0.016 & 0.047 \\
An. albimanus / An. gambiae & 568 & $223,224,142$ & 100 & 0.076 & 0.033 & 0.034 & 0.029 & 0.025 & 0.051 \\
\hline
\end{tabular}

and/or spatial position in the nucleus that restrict chromosome rearrangements. However, the experimental disruption of one of the largest conserved genomic regions in $D$. melanogaster caused an unexpectedly small phenotypic effect, namely alteration of odorant perception by flies [52]. Moreover, this change in odorant perception did not correlate with changes in gene expression within the disrupted conserved synteny block. We observed a tendency of the largest synteny blocks to concentrate close to the ends of the chromosome arms and to avoid the middle part of the arms (Figs. 5 and 6). Subtelomeric and pericentromeric chromosome regions are located at the nuclear periphery, and perhaps this feature restricts their ability to participate in long-range rearrangements. Indeed, a study in Drosophila has found that the largest conserved chromosomal regions are enriched in proteins Lamin and SUUR located at the nuclear periphery [53]. According to the systematic study of 53 chromatin proteins in Drosophila cells, Lamin and SUUR characterize transcriptionally inert "black" type of five principal chromatin types [54]. A previous three-species comparison of physical maps within subgenus Cellia [55] revealed that the autosomal arms differ in their tolerance to the distribution of conserved gene orders. If a block on e 2 was conserved between two mosquito species, it was likely disrupted in the third species. In contrast, all identified synteny blocks remained preserved on e4, suggesting the existence of arm-specific constraints to breakage [55]. However, our comparative genomic study demonstrated the highest concentration of largest conserved synteny blocks in both $\mathrm{e} 2$ and $\mathrm{e} 4$. Also, the minimum number of largest conserved synteny blocks was found not on e2 but on e3 (Figs. 5 and 6), suggesting that the dynamics of autosomal breakage differ between Cellia and other subgenera.

\section{Conclusions}

The physical genome map developed for the European malaria vector $A n$. atroparvus in this study demonstrates the power of chromosome-based assemblies for understanding genome evolution. The chromosome rearrangements identified here would be impossible to observe with routine cytogenetic techniques or with unmapped genome assemblies. We found that chromosomal arms in malaria mosquitoes can exchange their genetic material by partial-arm translocations. This observation challenges the presumed syntenic relationships of chromosomal arms among Anopheles species. Instead, the genetic content of a chromosome element cannot be assumed to be conserved across anophelines. Our findings suggests that the ancestral chromosome elements retain their integrity in subgenus Cellia, but not in subgenera Anopheles and Nyssorhynchus. The study supports the previously identified phenomenon of the rapid fixation of $\mathrm{X}$ chromosomal rearrangements. Finally, our data suggest the existence of mechanisms that govern the chromosomal arm and lineage specificity in rates of gene order disruption during the malaria mosquito evolution.

Table 6 Comparison of genome assemblies and mapped genomes for malaria mosquitoes

\begin{tabular}{|c|c|c|c|c|c|c|c|c|}
\hline Species & $\begin{array}{l}\text { Original } \\
\text { assembly }\end{array}$ & $\begin{array}{l}\text { Total } \\
\text { scaffolds }\end{array}$ & $\begin{array}{l}\text { Mapped } \\
\text { scaffolds }\end{array}$ & $\begin{array}{l}\text { Scaffold } \\
\text { N50, bp }\end{array}$ & $\begin{array}{l}\text { Total } \\
\text { length, Mb }\end{array}$ & $\begin{array}{l}\text { Mapped } \\
\text { length, Mb }\end{array}$ & Mapped, \% & Reference \\
\hline An. albimanus & AalbS1 & 204 & 40 & $18,068,499$ & 170.5 & 167.4 & 98.2 & {$[25]$} \\
\hline An. atroparvus & AatrE1 & 1371 & 56 & $9,206,694$ & 224.3 & 200.9 & 89.6 & This study \\
\hline An. arabiensis & AaraD1 & 1214 & 50 & $5,604,218$ & 246.6 & 216.3 & 87.7 & {$[56]$} \\
\hline An. gambiae & AgamP3 & 8 & 5 & $49,364,325$ & 273.1 & 230.2 & 84.3 & [43] \\
\hline An. stephensi & Astel2 & 23,371 & 86 & $1,591,355$ & 221.3 & 137.14 & 62 & {$[14]$} \\
\hline An. stephensi & AsteS1 & 1100 & 101 & 837,295 & 225 & 92.83 & 41 & {$[24]$} \\
\hline An. sinensis & AsinC2 & 9592 & 52 & 814,231 & 220.8 & 79.3 & 35.9 & {$[23]$} \\
\hline An. funestus & AfunF1 & 1392 & 103 & 671,960 & 225.2 & 79.0 & 35.1 & {$[24]$} \\
\hline
\end{tabular}




\section{Additional files}

Additional file 1: Table S1. Sizes, coordinates, and chromosomal positions of mapped An. atroparvus scaffolds. (XLSX $52 \mathrm{~kb}$ )

Additional file 2: Table S2. Scaffold-paired adjacencies in the An. atroparvus genome assembly. (XLSX $14 \mathrm{~kb}$ )

Additional file 3: Table S3. Lengths of pericentromeric-conserved synteny blocks in Anopheles. (DOCX $18 \mathrm{~kb}$ )

Additional file 4: Figure S1. A phylogenetic tree and types of rearrangements determined by the MGR program. A) Reconstructed phylogenetic tree determines a minimum number of rearrangements between each modern karyotype and the putative ancestral karyotype. B) Number and types of rearrangements between An. gambiae and putative ancestral species. C) Number and types of rearrangements between An. atroparvus and putative ancestral species. D) Number and types of rearrangements between An. albimanus and putative ancestral species. E) Number and types of rearrangements between An. gambiae and An. atroparvus. F) Number and types of rearrangements between $A n$. gambiae and An. albimanus. G) Number and types of rearrangements between An. atroparvus and An. albimanus. (TIF 1384 kb)

\section{Abbreviations}

Bp: Base pair; E: Element; GRIMM: Genome Rearrangements in Man and Mouse; kb: Kilobase; Mb: Megabase; MYA: Million years ago

\section{Acknowledgements}

We thank Melissa Wade for proofreading the text.

\section{Funding}

The study was performed using the Russian Science Foundation grant № 15-14-20011 to IVS. The funding agencies had no role in the design of the study, in the collection, analysis, and interpretation of data, and in the writing of the manuscript.

\section{Availability of data and materials}

All data are available in the main paper and in additional files. VectorBase has handled the public release of the An. atroparvus chromosomal genome assembly, and the data are available via VectorBase (https:// www.vectorbase.org/organisms/anopheles-atroparvus). All source codes are available on the github repository (https://github.com/seaman248/An.atroparvus-genome-comparison).

\section{Authors' contributions}

IVS and MVS conceived and designed the experiments. GA, AN, and SB performed the experiments and bioinformatics analyses. VNS provided resources and made contributions to conception and discussion of the study. GA, SB, IVS, and MVS conducted data analysis and wrote the manuscript. All authors read and approved the final manuscript.

\section{Ethics approval and consent to participate}

Not applicable

\section{Competing interests}

The authors declare that they have no competing interests.

\section{Publisher's Note}

Springer Nature remains neutral with regard to jurisdictional claims in published maps and institutional affiliations.

\section{Author details}

'Laboratory of Ecology, Genetics and Environmental Protection, Tomsk State University, 36 Lenin Avenue, Tomsk 634050, Russia. ${ }^{2}$ Department of Entomology, Fralin Life Science Institute, Virginia Polytechnic Institute and State University, 360 West Campus Drive, Blacksburg, VA 24061, USA.
Received: 26 October 2017 Accepted: 12 April 2018

Published online: 23 April 2018

\section{References}

1. Larkin DM, Pape G, Donthu R, Auvil L, Welge M, Lewin HA. Breakpoint regions and homologous synteny blocks in chromosomes have different evolutionary histories. Genome Res. 2009;19(5):770-7.

2. Ortiz-Barrientos D, Engelstadter J, Rieseberg LH. Recombination rate evolution and the origin of species. Trends Ecol Evol. 2016;31(3):226-36.

3. Puig M, Castellano D, Pantano L, Giner-Delgado C, Izquierdo D, Gaya-Vidal M, Lucas-Lledo Jl, Esko T, Terao C, Matsuda F, et al. Functional impact and evolution of a novel human polymorphic inversion that disrupts a gene and creates a fusion transcript. PLoS Genet. 2015:11(10):e1005495.

4. Lupianez DG, Kraft K, Heinrich V, Krawitz P, Brancati F, Klopocki E, Horn D, Kayserili H, Opitz JM, Laxova R, et al. Disruptions of topological chromatin domains cause pathogenic rewiring of gene-enhancer interactions. Cell. 2015;161(5):1012-25.

5. Bowers JE, Chapman BA, Rong J, Paterson AH. Unravelling angiosperm genome evolution by phylogenetic analysis of chromosomal duplication events. Nature. 2003:422(6930):433-8.

6. Murphy WJ, Pevzner PA, O'Brien SJ. Mammalian phylogenomics comes of age. Trends Genet. 2004;20(12):631-9.

7. Coghlan A, Eichler EE, Oliver SG, Paterson AH, Stein L. Chromosome evolution in eukaryotes: a multi-kingdom perspective. Trends Genet. 2005; 21(12):673-82.

8. Schaeffer SW, Bhutkar A, McAllister BF, Matsuda M, Matzkin LM, O'Grady PM, Rohde C, Valente VL, Aguade M, Anderson WW, et al. Polytene chromosomal maps of 11 Drosophila species: the order of genomic scaffolds inferred from genetic and physical maps. Genetics. 2008;179(3):1601-55.

9. White GB. Academic and applied aspects of mosquito cytogenetics. In: Blackman RL, Hewitt G, Ashburner M, editors. Insect cytogenetics. Oxford: Blackwell; 1981. p. 245-74.

10. Muller HJ. Bearings of the Drosophila work on systematics. In: Huxley J, editor. The new systematics. Oxford: Clarendon Press; 1940. p. 185-268.

11. Sharakhova MV, Peery A, Antonio-Nkondjio C, Xia A, Ndo C, AwonoAmbene P, Simard F, Sharakhov IV. Cytogenetic analysis of Anopheles ovengensis revealed high structural divergence of chromosomes in the Anopheles nili group. Infect Genet Evol. 2013;16:341-8.

12. Green $C$, Hunt $R$. Interpretation of variation in ovarian polytene chromosomes of Anopheles funestus Giles, A. parensis Gillies, and A. aruni. Genetica. 1980;51:187-95.

13. Zdobnov EM, von Mering C, Letunic I, Torrents D, Suyama M, Copley RR, Christophides GK, Thomasova D, Holt RA, Subramanian GM, et al. Comparative genome and proteome analysis of Anopheles gambiae and Drosophila melanogaster. Science. 2002;298(5591):149-59.

14. Jiang X, Peery A, Hall A, Sharma A, Chen XG, Waterhouse RM, Komissarov A, Riehl MM, Shouche Y, Sharakhova MV, et al. Genome analysis of a major urban malaria vector mosquito, Anopheles stephensi. Genome Biol. 2014;15(9):459.

15. Xia A, Sharakhova MV, Leman SC, Tu Z, Bailey JA, Smith CD, Sharakhov IV. Genome landscape and evolutionary plasticity of chromosomes in malaria mosquitoes. PLoS One. 2010;5(5):e10592.

16. Cornel AJ, Collins FH. Maintenance of chromosome arm integrity between two Anopheles mosquito subgenera. J Hered. 2000;91(5):364-70.

17. Sharakhova MV, Antonio-Nkondjio C, Xia A, Ndo C, Awono-Ambene P, Simard F, Sharakhov IV. Cytogenetic map for Anopheles nili: application for population genetics and comparative physical mapping. Infect Genet Evol. 2011;11(4):746-54

18. Sharakhov IV, Sharakhova MV, Mbogo CM, Koekemoer LL, Yan G. Linear and spatial organization of polytene chromosomes of the African malaria mosquito Anopheles funestus. Genetics. 2001;159(1):211-8.

19. Sharakhov IV, Serazin AC, Grushko OG, Dana A, Lobo N, Hillenmeyer ME, Westerman R, Romero-Severson J, Costantini C, Sagnon N, et al. Inversions and gene order shuffling in Anopheles gambiae and A. funestus. Science. 2002;298(5591):182-5.

20. Sharakhova MV, Antonio-Nkondjio C, Xia A, Ndo C, Awono-Ambene P, Simard F, Sharakhov IV. Polymorphic chromosomal inversions in Anopheles moucheti, a major malaria vector in Central Africa. Med Vet Entomol. 2014 28(3):337-40. 
21. Artemov GN, Sharakhova MV, Naumenko AN, Karagodin DA, Baricheva EM, Stegniy VN, Sharakhov IV. A standard photomap of ovarian nurse cell chromosomes in the European malaria vector Anopheles atroparvus. Med Vet Entomol. 2015;29(3):230-7.

22. Liang J, Sharakhova MV, Lan Q, Zhu H, Sharakhov IV, Xia A. A standard cytogenetic map for Anopheles sinensis and chromosome arm homology between the subgenera Anopheles and Cellia. Med Vet Entomol. 2014;28:26-32.

23. Wei Y, Cheng B, Zhu G, Shen D, Liang J, Wang C, Wang J, Tang J, Cao J, Sharakhov IV, et al. Comparative physical genome mapping of malaria vectors Anopheles sinensis and Anopheles gambiae. Malar J. 2017;16(1):235.

24. Neafsey DE, Waterhouse RM, Abai MR, Aganezov SS, Alekseyev MA, Allen JE, Amon J, Arca B, Arensburger P, Artemov G, et al. Highly evolvable malaria vectors: the genomes of 16 Anopheles mosquitoes. Science. 2015;347(6217):1258522.

25. Artemov GN, Peery AN, Jiang X, Tu Z, Stegniy VN, Sharakhova MV, Sharakhov IV. The physical genome mapping of Anopheles albimanus corrected scaffold misassemblies and identified interarm rearrangements in genus Anopheles. G3 (Bethesda). 2017;7(1):155-64.

26. Harbach RE. The phylogeny and classification of Anopheles. In: Manguin S, editor. Anopheles mosquitoes - new insights into malaria vectors. London: InTech; 2013. p. 3-55.

27. Sinka ME, Bangs MJ, Manguin S, Coetzee M, Mbogo CM, Hemingway J, Patil AP, Temperley WH, Gething PW, Kabaria CW, et al. The dominant Anopheles vectors of human malaria in Africa, Europe and the Middle East: occurrence data, distribution maps and bionomic precis. Parasit Vectors. 2010;3(1):117.

28. Sainz-Elipe S, Latorre JM, Escosa R, Masia M, Fuentes MV, Mas-Coma S, Bargues MD. Malaria resurgence risk in southern Europe: climate assessment in an historically endemic area of rice fields at the Mediterranean shore of Spain. Malar J. 2010;9:221.

29. Bueno-Mari R, Jimenez-Peydro R. Study of the malariogenic potential of eastern Spain. Trop Biomed. 2012;29(1):39-50.

30. Capinha C, Gomes E, Reis E, Rocha J, Sousa CA, do Rosario VE, Almeida AP. Present habitat suitability for Anopheles atroparvus (Diptera, Culicidae) and its coincidence with former malaria areas in mainland Portugal. Geospat Health. 2009;3(2):177-87.

31. Cailly P, Balenghien T, Ezanno P, Fontenille D, Toty C, Tran A. Role of the repartition of wetland breeding sites on the spatial distribution of Anopheles and Culex, human disease vectors in southern France. Parasit Vectors. 2011; 4:65.

32. Danabalan R, Monaghan MT, Ponsonby DJ, Linton YM. Occurrence and host preferences of Anopheles maculipennis group mosquitoes in England and Wales. Med Vet Entomol. 2014;28(2):169-78.

33. Frizzi G. Cytogenetic study of Anopheles maculipennis in Italy; extension of research to other species of Anopheles. Bull World Health Organ. 1953;9(3):335-44.

34. Jayakar SD, Laudani U, Marchi A, Tiepolo L, Fraccaro M. Genetics of sterility of Anopheles-atroparvus X Anopheles-labranchiae hybrids. J Genet. 1977; 63(1):1-14.

35. Tiepolo L, Diaz G, Laudani U. Differential DNA synthesis in homologous regions of hybrid polytenic chromosomes (Anopheles atroparvus $\times$ A labranchiae). Chromosoma. 1974;45(1):81-9.

36. Stegnii VN, Kabanova VM. Chromosome analysis of Anopheles atroparvus and A. maculipennis (Diptera, Culicidae). Russ J Zool. 1978;57(4):613-9.

37. Kitzmiller JB, Frizzi G, Baker RH. Evolution and speciation within the Maculipennis complex of the genus Anopheles. In: Wright JW, Pal R, editors. Genetics of insect vectors of disease. Amsterdam-London-New York: Elsevier Publishing Company; 1967. p. 151-210.

38. Stegniy VN. Population genetics and evolution of malaria mosquitoes. Tomsk: Tomsk State University Publisher; 1991.

39. George P, Sharakhova MV, Sharakhov IV. High-resolution cytogenetic map for the African malaria vector Anopheles gambiae. Insect Mol Biol. 2010;19(5):675-82.

40. Pevzner $P$, Tesler $G$. Genome rearrangements in mammalian evolution: lessons from human and mouse genomes. Genome Res. 2003;13(1):37-45.

41. Guy L, Kultima JR, Andersson SG. genoPlotR: comparative gene and genome visualization in R. Bioinformatics. 2010;26(18):2334-5.

42. Bourque G, Pevzner PA. Genome-scale evolution: reconstructing gene orders in the ancestral species. Genome Res. 2002;12(1):26-36.

43. Sharakhova MV, Hammond MP, Lobo NF, Krzywinski J, Unger MF, Hillenmeyer ME, Bruggner RV, Birney E, Collins FH. Update of the Anopheles gambiae PEST genome assembly. Genome Biol. 2007;8(1):R5.
44. Tesler G. GRIMM: genome rearrangements web server. Bioinformatics. 2002; 18(3):492-3.

45. Papaceit M, Juan E. Fate of dot chromosome genes in Drosophila willistoni and Scaptodrosophila lebanonensis determined by in situ hybridization. Chromosom Res. 1998;6(1):49-54.

46. Bhutkar A, Schaeffer SW, Russo SM, Xu M, Smith TF, Gelbart WM. Chromosomal rearrangement inferred from comparisons of 12 Drosophila genomes. Genetics. 2008;179(3):1657-80.

47. Segarra C, Lozovskaya ER, Ribo G, Aguade M, Hartl DL. P1 clones from Drosophila melanogaster as markers to study the chromosomal evolution of Muller's a element in two species of the obscura group of Drosophila. Chromosoma. 1995;104(2):129-36.

48. Lemeunier F, Ashburner MA. Relationships within the melanogaster species subgroup of the genus Drosophila (Sophophora). II. Phylogenetic relationships between six species based upon polytene chromosome banding sequences. Proc R Soc Lond B Biol Sci. 1976;193(1112):275-94.

49. Ranz JM, Maurin D, Chan YS, von Grotthuss M, Hillier LW, Roote J, Ashburner M, Bergman CM. Principles of genome evolution in the Drosophila melanogaster species group. PLoS Biol. 2007;5(6):e152.

50. Harbach RE, Kitching IJ. The phylogeny of Anophelinae revisited: inferences about the origin and classification of Anopheles (Diptera: Culicidae). Zool Scr. 2016:45(1):34-47.

51. Charlesworth B, Coyne JA, Barton NH. The relative rates of evolution of sex chromosomes and autosomes. Am Nat. 1987;130(7):113-46.

52. Diaz-Castillo C, Xia XQ, Ranz JM. Evaluation of the role of functional constraints on the integrity of an ultraconserved region in the genus Drosophila. PLoS Genet. 2012;8(2):e1002475.

53. Ranz JM, Diaz-Castillo C, Petersen R. Conserved gene order at the nuclear periphery in Drosophila. Mol Biol Evol. 2011;29:13-16.

54. Filion GJ, van Bemmel JG, Braunschweig U, Talhout W, Kind J, Ward LD, Brugman W, de Castro IJ, Kerkhoven RM, Bussemaker HJ, et al. Systematic protein location mapping reveals five principal chromatin types in Drosophila cells. Cell. 2010;143(2):212-24.

55. Sharakhova MV, Xia A, Leman SC, Sharakhov IV. Arm-specific dynamics of chromosome evolution in malaria mosquitoes. BMC Evol Biol. 2011:11(1):91.

56. Fontaine MC, Pease JB, Steele A, Waterhouse RM, Neafsey DE, Sharakhov IV, Jiang $X$, Hall AB, Catteruccia F, Kakani $E$, et al. Extensive introgression in a malaria vector species complex revealed by phylogenomics. Science. 2015; 347(6217):1258524.

\section{Ready to submit your research? Choose BMC and benefit from:}

- fast, convenient online submission

- thorough peer review by experienced researchers in your field

- rapid publication on acceptance

- support for research data, including large and complex data types

- gold Open Access which fosters wider collaboration and increased citations

- maximum visibility for your research: over $100 \mathrm{M}$ website views per year

At BMC, research is always in progress.

Learn more biomedcentral.com/submissions 